\title{
O jogar pós-fenomenológico
}

\author{
Emil Hammar \\ Doutor; University of Troms $\varnothing$, Noruega \\ Endereço de e-mail: emil.hammar@uit.no \\ Tradução: Breno Maciel Souza Reis \\ Universidade Federal do Rio Grande do Sul, Porto Alegre, RS, Brasil \\ brenomaciel@gmail.com \\ Revisão de tradução: Samyr Paz \\ Universidade Feevale \\ Universidade Federal do Rio Grande do Sul Porto Alegre, RS, Brasil \\ samyrpaz@gmail.com
}

\section{Resumo}

Este trabalho objetiva delinear os jogos digitais em ambientes virtuais em conjunção com o papel da tecnologia como um dos mediadores de mundo aos seres humanos, de acordo com a abordagem pós-fenomenológica de Ihde e o conceito de jogo e seu papel hermenêutico exposto por Gadamer. Com isso, defendemos que os jogos digitais, como uma tecnologia característica de nossa época, insere questões que atravessam os modos a partir dos quais nos inserimos no mundo e damos sentido às nossas experiências em relação ao mesmo, tanto subjetiva, quanto social, tecnológica e hermeneuticamente. Ao fim, são expostos possíveis encaminhamentos e desdobramentos para esta empreitada.

\section{Palavras-chave}

Jogos Digitais. Hermenêutica. Pós-Fenomenologia. Mediação Tecnológica. Jogar.

\section{Introdução}

Este artigo busca identificar uma compreensão dos jogos digitais em ambientes virtuais ${ }^{1}$ utilizando a abordagem pós-fenomenológica de Don Ihde (1990) sobre os modos pelos quais a tecnologia media o mundo aos seres humanos, em conjunção com a noção de

\footnotetext{
${ }^{1}$ Esse artigo se apoia na visão de Wittgenstein (2001) dos jogos como membros de uma família que compartilha semelhanças uns com os outros. Especificamente, meu foco é em um subtipo de jogos que possuem como condição de ocorrência ambientes virtuais, de acordo com Calleja (2001). Isso é feito para demarcar o escopo de análise e excluir versões digitais de jogos analógicos, como o Poker ou a Paciência.
} 
jogo 2 em Hans-Georg Gadamer (1993). Por meio dessa tentativa de entrelaçamento de teorias, aponto na direção de uma compreensão alternativa da relação entre lúdico e jogo não apenas como sendo dialética, mas também como social e eticamente relevantes quando do design e implementação do jogo enquanto tecnologia.

Inicialmente, destaco o conceito de mediação hermenêutica tecnológica de Ihde e o aplico aos jogos digitais como uma tecnologia. Considerando que tal aplicação conceitual aos jogos digitais necessita de uma definição conceitual de lúdico, subsequentemente eu utilizo a definição de lúdico de Gadamer para, posteriormente compreender a relação entre os jogadores $^{3}$ e os jogos digitais como tecnologia. Consequentemente, proponho uma visão ajustada sobre como os jogos digitais, enquanto uma tecnologia, mediam o mundo aos seus jogadores dada a compreensão dialética do jogo em Gadamer, de acordo com as implicações da proposta deste artigo. Finalmente, saliento objeções potenciais e futuros encaminhamentos analíticos e de pesquisa para os conceitos propostos.

Embora seja um desafio mesclar essas duas diferentes teorias sem cometer injustiças aos seus respectivos conceitos, minha avaliação é de que as teorias indicam um caminho potencialmente rico para a compreensão da atividade lúdica através da tecnologia ${ }^{4}$. Por isso, este artigo deve ser tomado como um elogio teórico, ou uma contribuição sobre como nos aproximamos de fenômenos complexos, tais como o lúdico e o jogo, e seu relacionamento dialético.

\section{Mediação tecnológica na forma de jogos digitais}

Nesta seção do trabalho, eu delineio e aplico conceitos de mediação tecnológica com o propósito de ilustrar como esses conceitos, oriundos de Ihde (1990) podem nos auxiliar a compreender como os jogos digitais funcionam como tecnologias e como nós, enquanto humanos, nos relacionamos com os mesmos. Levando em conta a variedade e complexidade de nossas relações com a tecnologia, Ihde defende que a tecnologia media a percepção a partir de quatro diferentes relações entre seres humanos e o mundo

\footnotetext{
2 Embora este trabalho não se apoie exclusivamente na questão estética gadameriana, é importante notar que, em minha aproximação na sua caracterização do lúdico, deve-se ter em mente que o aspecto hermenêutico da estética de Gadamer não é uma teoria sobre a arte, mas "mais um conjunto prático de observações contemplativas que potencializam o encontro com a arte" (DAVEY, 2011).

${ }^{3}$ Neste trabalho eu utilizo o termo jogador para me referir ao agente humano que se envolve com o jogo em questão.

4 Embora seja desafiador, isso não é impossível, e quando utilizamos diferentes teorias mutuamente complementares, frequentemente nós obtemos resultados frutíferos, como é defendido neste artigo.
} 
experienciado. Entretanto, devido ao escopo deste trabalho, eu destacarei e aplicarei apenas uma dessas relações, a mediação hermenêutica tecnológica5. Essa relação em particular é compreendida no discurso de Introna sobre as instâncias nas quais as tecnologias "funcionam como um referente imediato a algo além dela mesma" (INTRONA, 2011). Tal relação requer que a tecnologia possa mediar algo que necessite da interpretação pelo usuário para que se constitua uma 'percepção'. A descrição formal da mediação hermenêutica é a seguinte6:

\section{$I->($ tecnologia - mundo)}

A relação hermenêutica acima destacada ilustra como o ser humano percebe ou experiencia o mundo através da tecnologia. Verbeek cita o exemplo de um termômetro, o qual "revela um aspecto, a saber, a temperatura [do mundo]" (VERBEEK, 2005, p. 126)7, ilustrando assim como uma tecnologia específica informa ao seu usuário um estado do mundo.

Quando esta mediação tecnológica hermenêutica é aplicada aos jogos digitais8, testemunhamos o mesmo tipo de representação no ambiente virtual do jogo. Por exemplo, o jogador percebe e interpreta o ambiente virtual através da tecnologia requerida para executar e apresentar o jogo digital e o seu ambiente virtual em questão. Portanto, ao se engajar em um jogo e interpretar seus signos representacionais, o jogador é exposto ao design e à implementação do jogo digital. Deste modo, o jogo digital enquanto uma tecnologia afeta a interpretação do jogador do ambiente virtual referido. Como pontua Verbeek:

Muitas formas de mediação tecnológica são possíveis de transformar nosso acesso ao mundo de variadas maneiras, algumas das quais nos abrem novas formas de acesso inacessíveis à "percepção a olho nu", e algumas das quais estreitam esse acesso (VERBEEK, 2005, p. 144, tradução nossa)9.

Deste modo, o jogo digital como uma tecnologia projetada e implementada é capaz de alterar e afetar a compreensão e interpretação potenciais de um ambiente virtual

\footnotetext{
${ }^{5}$ As outras três relações são a incorporação, alteridade e relação de segundo plano, respectivamente.

${ }^{6}$ Formalizado por Verbeek, 2005, p. 126.

7 Ter em mente que este não é o caso de uma tecnologia que sinta a temperatura, mas ao invés, uma representação dela.

${ }^{8}$ Note-se que é certamente possível que outras mediações tecnológicas ocorram ao jogar um determinado jogo digital, porém o seu tratamento e a sua aplicação aos jogos digitais vão além do escopo deste artigo.

9 "Many forms of technological mediation are possible that transform our access to the world in myriad ways, some of which open up to us news ways of access unavailable do 'naked-eye perception', and some of which narrow this access".
} 
retratado. Entretanto, deve ser notado que Ihde afirma que os jogos digitais não são relações especificamente hermenêuticas ou incorporadas, mas ao invés, uma relação de alteridade ${ }^{10}$. Ele defende que

Não há dúvida da correspondência entre a imaginação da tela e o mundo real. 0 mundo-na-tela é um mundo que é construído, não copiado. [...] na minha antiga terminologia de relações humanas, esta é uma relação de alteridade em que a entidade maquínica torna-se um quase-outro ou quase-mundo com o qual o ator humano se relaciona (IHDE, 2002, p. 81, grifos do autor, tradução nossa) ${ }^{11}$.

Embora Ihde entenda nosso envolvimento com os jogos digitais como uma forma de relação com a alteridade, a citação acima parece se apoiar em uma visão de mundo na qual algumas representações correspondem à realidade ${ }^{12}$ (p. ex., um termômetro que representa a temperatura atual do mundo), enquanto que outras representações são meros constructos (p. ex., um jogo digital que representa um ambiente virtual). Entretanto, pode-se argumentar que um jogo digital, no qual o jogador encena o jogo de, por exemplo, um cavaleiro branco lutando contra dragões, parcialmente se refere à realidade (um cavaleiro branco) e, parcialmente, se refere a uma construção humana (dragões), indicando assim que os jogos digitais com ambientes virtuais não são exclusivamente 'quasi' e separados da realidade. A esse respeito, os jogos digitais se baseiam em noções da realidade, apesar de seu status de objetos virtuais. Certamente há diferenças entre representações em jogos digitais e representações em modelos científicos explicativos; entretanto, considerando como os jogos digitais se baseiam em interpretações do mundo, é difícil vislumbrar como eles podem ser classificados inteiramente como quasi-mundos, enquanto que modelos explicativos científicos não são. Por isso, considero difícil ver como Ihde é capaz de, plausivelmente, fazer distinções não-arbitrárias entre jogos digitais como representações de 'quasi-mundos' e diferentes representações científicas do mundo como representações da realidade.

Além disso, minha interpretação é a de que relações hermenêuticas ocorrem

\footnotetext{
${ }^{10}$ A relação de alteridade é caracterizada na citação de Introna como uma relação na qual "a tecnologia é experienciada como um ser que é de outra forma, diferente de mim, uma tecnologia-como-outro. Na minha relação com essas tecnologias, elas parecem exibir um 'mundo próprio" (INTRONA, 2011).

11 " $[. .$.$] there is no question of a correspondence between the screen imagining and the real world. The$ world-on-the-screen is a fictive world that is constructed, not copied. [...] In my earlier human-technology relations terminology, this is an alterity relation in which the machinic entity becomes a quasi-other or quasi-world with which the human actor relates."

12 Tal visão sobre a verdade, ou seja, a teoria da correspondência da verdade, enfrenta algumas críticas filosóficas, mas tal tratamento está além do escopo deste artigo. Para uma visão crítica e discussão da correspondência da verdade, ver David (2013).
} 
quando nós nos engajamos em um jogo digital em virtude do fato dos jogadores não apenas interpretarem os "signos representacionais" (CALLEJA, 2011, p. 12) do jogo, mas também configurarem o estado do jogo ${ }^{13}$. Sellinger (2006) também pontua em "Postphenomenology: A critical guide to Ihde" que

Para jogar a maioria dos videogames, deve-se entrar em relações hermenêuticas e de incorporação. Sem a habilidade de usar um joystick ou interpretar os gráficos [do jogo] como significantes, o jogo não pode ser efetivamente jogado (SELLINGER, 2006, p. 6, tradução nossa) ${ }^{14}$.

Assim, defendo que é possível aplicar o conceito de mediação hermenêutica aos jogos digitais representando um ambiente virtual 15 .

Em suma, o conceito pós-fenomenológico de mediação tecnológica na forma de uma relação hermenêutica é capaz de caracterizar a natureza por meio da qual os jogos digitais mediam o seu ambiente virtual para o jogador. A seguir, consideraremos como a atividade de jogar pode afetar a relação hermenêutica já proposta entre o jogador e o jogo digital.

\section{0 jogar como uma relação dialética entre o jogador e o jogo}

É importante manter em mente o conceito de lúdico quando se aplica a relação mediadora acima descrita ao ato de jogar o jogo digital, com o modo com o qual nós nos envolvemos com as tecnologias, ou especificamente, os jogos digitais, podem afetar como nós entendemos a própria tecnologia (VERBEEK, 2005, p. 136). A despeito de muitas sugestões de entendimento sobre como o lúdico existe ${ }^{16}$, penso que a caracterização do lúdico feita por Gadamer ${ }^{17}$ (1993) é relevante para os propósitos deste trabalho, bem como

13 Alguns argumentos dentro dos game studies corroboram essa noção de interpretação e configuração. Ver Arsenault e Perron (2007), Sicart (2009), e Aarseth (1997, p. 40).

14 "To play most of video games, one must enter into embodied and hermeneutic relations. Without the ability to use a joystick or interpret graphics as significant, the game cannot be effectively played".

${ }^{15}$ Alternativamente, se meu argumento necessita estar alinhado com a defesa de Ihde sobre os jogos digitais constituindo uma relação de alteridade, pode-se argumentar que um possível ambiente virtual exista independentemente de uma tecnologia, permitindo assim que nós analisemos como o ambiente virtual é hermeneuticamente mediado ao jogador.

16 Entre estas encontram-se Huizinga (2007), Caillois (1990), Ehrman (1968), Dekoven (2002), Schechner (1988), SuttonSmith (1997), Malaby (2007), e Myers (2010). Todas estas visões distintas sobre o complexo fenômeno lúdico podem contribuir para uma compreensão posterior do conceito; mesmo assim, cobrir o espectro fluido e quase indeterminável do lúdico está além do escopo deste artigo.

17 Embora Gadamer introduza o conceito de jogo com o objetivo de estabelecer sua hermenêutica estética particular, meu entendimento é que sua caracterização de jogo é suficientemente aplicável no domínio dos game studies, de modo a aprofundar posteriormente nosso entendimento do que caracteriza a atividade do jogo e o relacionamento entre o jogo e o jogador. 
auxilia a levar em conta as nuances e complexidades do processo de interpretação e configuração de um jogo digital, mantendo em mente a relação entre o jogador e o jogo.

Em suma, Gadamer propõe que jogar como uma atividade pressupõe um movimento contínuo de vai-e-vem entre sujeito e objeto, ou entre o jogador e o jogo (GADAMER, 1993, p. 103). Esse movimento de vai-e-vem entre o jogador e o jogo não se refere nem ao sujeito sendo jogado nem ao objeto com o qual o se joga, mas um movimento em si mesmo; e, assim, jogar não pode ser reduzido nem ao sujeito que joga (ou jogador) nem ao objeto que é jogado ${ }^{18}$. Além disso, durante esse movimento ou processo dialético entre jogador e jogo, é inviável se referir ao jogador como o sujeito, porque "o jogo, ele mesmo, é uma transformação tal que a identidade daquele que joga não continua existindo para ninguém [...]. Os jogadores (ou poetas) não existem mais, existe apenas o que é jogado por eles" (GADAMER, 2015, p. 167). De acordo com isso, durante esse processo dialético, o jogador é subjugado ao jogo, por exemplo, o jogo domina o jogador:

[...] todo jogar é um ser-jogado. [...] o verdadeiro sujeito do jogo não é o jogador mas o próprio jogo. É o jogo que mantém o jogador a caminho (em seu encanto), que o enreda no jogo e que o mantém nele (GADAMER, 2015, p. 160, grifos do autor).

Deste modo, o jogador se entrega ao jogo, de modo que ele ou ela não jogam, mas sim são jogados. Por exemplo, quando do engajamento do jogador em um determinado jogo digital, o jogador se sujeita às "regras e estruturas do jogo" (AARSETH, 2007, p. 107), implicando assim que o processo dialético do jogo reside "[...] no fato de eles prefigurarem e ordenarem cada vez diferente o vaivém do movimento do jogo. 0 que constitui a essência do jogo são as regras e disposições que prescrevem o preenchimento do espaço lúdico" (GADAMER, 2015, p. 160). Essa noção de como os jogadores são automaticamente sujeitados ao próprio jogo também remete à noção de Ihde de que como nós, ao usarmos tecnologias, também somos usados por essas próprias tecnologias ${ }^{19}$. Esse aspecto em particular é enfatizado porque ele aponta na direção de como o design e a implementação dos jogos digitais como tecnologias podem restringir o(s) jogador(es) através das regras e estruturas dos jogos, p. ex., os códigos do jogo (MYERS, 2010, p. 16).

Entretanto, a subjugação do jogador ao jogo não implica que é possível reduzir o

\footnotetext{
18 "O modo de ser do jogo não permite que quem joga se comporte em relação ao jogo como se fosse um objeto" (GADAMER, 2015, p. 155).

19 “O que se destaca inicialmente é que toda relação humano-tecnologia é uma relação de via dupla. À medida em que eu uso ou emprego uma tecnologia, eu também sou usado e empregado pela tecnologia também” (IHDE, 2002, p. 137, tradução nossa).
} 
ato de jogar às propriedades ontológicas do jogo:

Assim como com o jogo, arte não pode ser entendida pela referência isolada às suas ferramentas e equipamentos. Certamente que a arte requer materiais, bem como uma apreciação de como estas ferramentas específicas foram talvez utilizadas. Ainda assim, nem a arte nem o jogo são constituídos [apenas] por seus equipamentos (DAVEY, 2011, s/p, tradução nossa) ${ }^{20}$.

O que se alega não é, portanto, que um jogo seja incapaz de ser reduzido à sua intenção, seu material ou sua convenção, mas "ao invés, que cada um desses elementos possui seus próprios [domínios] quando tomados no interior do jogar do jogo" (DAVEY, 2011, ênfase do autor, tradução nossa) ${ }^{21}$. Isso pode ser exemplificado em instâncias como o 'jogo transgressivo' (AARSETH, 2007) e o 'mau jogo' (MYERS, 2010), ambos indicando que a atividade de jogar é algo mais que os elementos que o jogo digital prescreve [ao jogador].

Em suma, eu caracterizo jogar como um movimento dialético constante de vai-evem entre o jogador e o jogo, no qual o jogador é sujeitado às estruturas do jogo, as quais são interpretadas pelo jogador que, retroativamente, altera ou renova a experiência de jogar por meio da ação de jogar. Esse ato de jogar é irredutível tanto ao jogador quanto às estruturas do jogo. Com essa caracterização em mente, posso agora combinar o conceito proposto de mediação hermenêutico-tecnológica com a noção de jogo em Gadamer.

\section{Mesclando o jogo dialético e mediação tecnológica}

Relembrando a aplicação do conceito de mediação hermenêutico-tecnológica de Ihde no domínio dos jogos digitais, bem como também a noção de jogo em Gadamer como um processo dialético entre o jogo e o jogador, é agora possível estabelecer um modelo aplicável aos jogos digitais:

$$
I<->\text { (tecnologia-mundo) }
$$

Em nosso envolvimento ou ao jogar a tecnologia de um jogo digital, não se trata

\footnotetext{
20 "Like with the game, art is not to be understood by reference to its tools and equipment alone. Art requires materials certainly, and an appreciation of how a specific tool might be used. Yet neither game nor art is constituted by its equipment".

21 "rather that each of these elements come into their own when taken up within the playing of the game"
} 
apenas do ambiente virtual do jogo retratado, mas também uma questão de jogar com a tecnologia e com seu ambiente virtual. Essa nova conjunção entre as duas teorias propostas é instanciada como um relacionamento dialético entre o jogador e o jogo quando o jogador se engaja com um jogo digital que media hermeneuticamente o seu ambiente virtual. Seguindo o movimento de vai-e-vem entre jogador e jogo, a tecnologia de um jogo digital não está apenas mediando seu ambiente virtual, mas o jogador, por sua vez, está também interpretando e reconfigurando o jogo digital e seu ambiente virtual. Deste modo, este novo modelo conceitual ilustra como o relacionamento entre jogador e jogo é dialético e hermeneuticamente mediado. Consequentemente, esta abordagem permite futuras compreensões e análises da relação entre o jogador e o jogo digital como uma tecnologia, como será destacado a seguir.

\section{Implicações}

Dado esta nova compreensão de como o [ato de] jogar pode ser visto como uma relação dialética entre o jogador e o jogo mediando um ambiente virtual, o conceito das relações humano-tecnologia fornece um panorama de como os jogadores se engajam com tecnologias cotidianas como os jogos digitais "de uma maneira que pode facilitar nossas considerações sobre as implicações sociais e éticas das tecnologias de informação" (INTRONA, 2011, s/p, tradução nossa)22; por exemplo, como o modo como os jogos digitais são projetados e implementados pode levar a certas considerações sociais e éticas. Adicionalmente, é possível analisar posteriormente como os jogadores são capazes de transgredir, através de [seus modos de] jogar ou interpretar e configurar um determinado jogo, as estruturas do jogo digital em questão; ao mesmo tempo observando como o jogo se impõe ao jogador, desse modo possibilitando uma análise da interpendência dialética entre os dois. Além disso, pode-se argumentar que teorias que reduzem a interpretação e temas de um determinado jogo às suas estruturas ou procedimentos básicos ${ }^{23}$ são insuficientes, se desejamos compreender como [o ato de] jogar pode ser um entrelaçamento de elementos entre o jogador e o jogo.

Desta forma, a abordagem pós-fenomenológica, em termos de entendimento da mediação hermenêutica do ambiente virtual, torna possível analisar o projeto de um

\footnotetext{
22 "In a manner that can facilitate our considerations of the social and the ethical implications of information technology". ${ }^{23}$ Conforme Flanagan (2009), Swain e Bathwaite (2010) e talvez, em alguma medida, a Bogost (2009).
} 
determinado jogo digital nas formas pelas quais ele media algo que necessita interpretação e, em contrapartida, a interpretação e configuração do [próprio] jogo digital. Assim como os conceitos de Ihde foram aplicados para determinar como os objetos tecnológicos mediam seu desencobrimento e seu mundo referenciado ${ }^{24}$; portanto estes conceitos podem ser aplicados ao design e ao [ato de] jogar jogos digitais em ambientes virtuais. Esse aspecto da compreensão da mediação hermenêutica dos jogos digitais é também benéfico quando se considera o ponto inicial do modo pelo qual os jogadores de jogos (ou usuário de tecnologia) estão, também, sendo jogados pelos jogos (ou usados pela tecnologia). Tendo em mente, entretanto, que a tecnologia não cria um modo único de revelar o mundo (IHDE, 1990, p. 159) - mas, ao contrário, cultiva "a proliferação de diferentes modos de ver no interior de nossa cultura" (VERBEEK, 2005, p. 144, tradução nossa) ${ }^{25}$.

Finalmente, esta abordagem destaca o status ontológico de um dado ambiente virtual em um jogo digital, apontando assim para investigações posteriores da relação entre experiências propiciadas dentro de um ambiente virtual e o status das ações virtuais e a correspondência no [próprio] mundo virtual ou, na falta dela, com a realidade.

\section{Objeções potenciais}

Embora a identificação de uma possível abordagem para se compreender os jogos digitais é feita apenas provisoriamente neste artigo, pode-se levantar objeções quanto à validade dos conceitos das seguintes formas.

Pode-se argumentar quanto ao delineamento do jogador e do jogo como entidades separadas, fazendo assim com o que o argumento do artigo assuma uma relação falaciosa entre sujeito-objeto. Considerando a premissa fenomenológica de que os seres humanos são sempre seres no mundo, não faz sentido sugerir uma distinção entre sujeito e objeto, ou entre jogador e jogo. Quanto a isso, Verbeek enfrenta tal objeção ao enfatizar que o fato de que a mediação sempre constitui de pronto a relação entre sujeito e objeto:

A relação entre sujeito e objeto já sempre precede os próprios sujeitos e objetos, o que implica que o sujeito e o objeto são mutuamente constituídos em sua inter-relação. [...] 0 que humanos são e o que seu mundo é recebem suas formas por mediações de [diferentes] artefatos

\footnotetext{
24 "Uma tecnologia hermenêutica, afinal, proporciona uma representação da realidade, a qual implica que o projeto de uma tal tecnologia predetermina quais aspectos da realidade tornam-se perceptíveis pelas mesmas e de que formas" (VERBEEK, 2005, p. 134, tradução nossa).

25 "The proliferation of different ways of seeing within our culture".
} 
(VERBEEK, 2005, p. 129-130, tradução nossa) ${ }^{26}$.

A relação sujeito-objeto, ou jogador-jogo, não possui prioridade epistemológica frente a própria relação. A mediação entre o jogador e o jogo precede tanto o jogador quanto o jogo no ato de jogar, assim como defende Gadamer (GADAMER, 1993, p. 293), por exemplo, a mediação ou relação entre o jogador e o jogo equivale em uma constituição mútua - tanto do jogador quanto do jogo.

\section{Conclusão}

Este artigo é uma tentativa de apontar na direção de uma abordagem pósfenomenológica para o entendimento da atividade de jogar através da tecnologia, especificamente jogos digitais em ambientes virtuais. Inicialmente, apresentei o conceito de mediação tecnológica-hermenêutica de Ihde e esclareci como o conceito pode ser aplicado aos jogos digitais. Para aprimorar ainda mais essa aplicação, coloquei a noção de jogo em Gadamer para destacar e enfatizar como o jogo, enquanto uma atividade, é um movimento de vai-e-vem dialético entre o jogador e o jogo. Como resultado, essa ênfase no jogo como um processo constantemente dialético altera a mediação entre o humano, a tecnologia e o ambiente virtual no sentido de se analisar o envolvimento dos jogos não apenas mediando o jogo para o jogador, mas também interpretando e configurando na direção do jogador para o jogo. Finalmente, incluí potenciais objeções que, talvez, demandem maiores investigações.

Investidas posteriores em relação à aplicação das outras relações expostas por Ihde, a saber as relações de incorporação e alteridade, podem aprimorar potencialmente a precisão analítica do conceito e garantir uma avaliação mais estável e holística do que significa jogar um jogo digital. Assim, ela pode se confirmar benéfica à investigação e análise dos modos pelos quais os jogos são projetados para representar ambientes virtuais, como estes são representados, e se estas representações são ou não alteradas no ato de jogá-los.

\footnotetext{
26 "The relation between subject and object always already precedes the subject and the object themselves, which implies that the subject and the object are mutually constituted in their interrelation. [...] What humans are and what their world is receive their form by artifactual mediation".
} 


\section{Referências}

AARSETH, Espen. Cybertext: perspectives on ergodic literature. Baltimore: The Johns Hopkins University Press, 1997.

Bogost, Ian. Persuasive games: The expressive power of videogames. Cambridge; London: The MIT Press, 2007.

BRATHWAITE, Brenda; SHARP, John. The Mechanic Is the Message: A Post Mortem in Progress. In: SCHRIER, Karen; GIBSON, David (Ed.). Ethics and Game Design: Teaching Values Through Play. [s.l]: Information Science Reference, 2010. p. 311-329.

CAILLOIS, R. Os jogos e os homens: a máscara e a vertigem. Lisboa: Cotovia. 1990.

CALLEJA, Gordon. In-game: from immersion to incorporation. Cambridge: MIT Press, 2011.

DAVEY, N. Gadamer's Aesthetics. The Stanford Encyclopedia of Philosophy (Archives). 2007.

DEKOVEN, B.. Talking About What We're Looking For. In: DEKOVEN, B.. The Well-Played Game: A Playful Path to Wholeness. [s.l]: Writers Club Pr, 2002. p. 1-14.

EHRMAN, Jacques; LEWIS, Cathy; LEWIS, Phil. Homo ludens revisited. Yale French Studies, [s.l], n. 41, p.31-57, 1968.

FLANAGAN, Mary. Critical play: radical game design. Massachusetts: MIT Press, 2009.

GADAMER, Hans-Georg. Truth and Method. New York: Continuum, 1993.

GADAMER, Hans-Georg. Verdade e método I: traços fundamentais de uma hermenêutica filosófica. 15a ed. Petrópolis: Vozes, 2015.

HUIZINGA, J. Homo ludens: o jogo como elemento da cultura. São Paulo: Perspectiva, 2007.

IHDE, Don. Technology and the Lifeworld: From Garden to Earth. Bloomington: Indiana University Press, 1990.

IHDE, Don. Bodies in technology. Minneapolis: University of Minnesota Press, 2002.

INTRONA, Lucas. Phenomenological Approaches to Ethics and Information Technology. In: STANDORF UNIVERSITY. Stanford Encyclopedia of Philosophy. [s.l]: Stanford University, 2011.

MALABY, Thomas M.. Beyond play: A new approach to games. Games And Culture, [s.l], v. 2, n. 2, p.95-113, 2007.

MYERS, David. Play redux. University of Michigan Press, 2010.

SCHECHNER, Richard. Playing. Play \& Culture, [s.l], v. 1, n. 1, p. 3-19, 1988. 
SELLINGER, Evan (Org.) Postphenomenology: a critical companion to Ihde. Albany: State University of New York Pressed. 2006.

SICART, Miguel. The ethics of computer games. Cambridge: MIT Press, 2009.

SUTTON-SMITH, Brian. The ambiguity of play. Cambridge; London: Harvard University Press, 1997.

SWAIN, Chris. The mechanic is the message: How to communicate values in games through the mechanics of user action and system response. In: SCHRIER, Karen; GIBSON, David (Ed.). Ethics and Game Design: Teaching Values Through Play. [s.l]: Information Science Reference, 2010. p. 217-235.

VERBEEK, Peter-Paul. What things do: philosophical reflections on technology, agency, and design. University Park: The Pennsylvania State University Press, 2005.

\title{
Postphenomenological play
}

\begin{abstract}
This paper aims to delineate the digital games in virtual environments and the role of technology as one of the mediators to the human world, according with the Ihde's postphenomenological approach and the Gadamer's concept of play and its hermeneutical role. Therefore, we argue that digital games, as a typical technology of contemporary society, bring in itself questions that cross the ways in which we are in our world, as well how we attribute sense to our experiences in relation to the same, both subjective, social, technological and hermeneutically. Finally, we present possible unfoldings for this enterprise.
\end{abstract}

\section{Keywords}

Digital Games. Hermeneutics. Post-Phenomenology.

Technological Mediation. Play. 